\title{
Changes in corticospinal facilitation of lower limb spinal motor neurons after spinal cord lesions
}

\author{
B Brouwer, J Bugaresti, P Ashby
}

\begin{abstract}
The projections from the cortex to the motor neurons of lower limb muscles were examined in 33 normal subjects and 16 patients with incomplete spinal cord lesions. Corticospinal neurons were excited by transcranial magnetic stimulation and the effects on single spinal motor neurons determined from peristimulus time histograms (PSTHs) of single tibialis anterior (TA) and soleus (SOL) motor units. In normal subjects magnetic stimulation produced a short latency facilitation of TA motor units but had little or no effect on SOL motor units. In the patients with spinal cord lesions magnetic stimulation also produced facilitation of TA but not SOL motor units; however, the mean latency of the TA facilitation was significantly longer (by about $14 \mathrm{~ms}$ ) in the patient group. The $F$ wave latencies were normal in all patients tested, suggesting that central rather than peripheral conduction was slowed. The duration of the period of increased firing probability (in TA motor units) was also significantly longer in the patients with spinal cord lesions. These changes may reflect the slowing of conduction and dispersal of conduction velocities in the corticospinal pathways as a consequence of the spinal cord lesion. No significant correlations were found between the delay of the TA facilitation and the clinical deficits in this group of patients.
\end{abstract}

Transcranial stimulation of the human motor cortex by electrical ${ }^{1}$ or magnetic ${ }^{2}$ stimuli produces contractions of contralateral limb muscles. The latency and brevity of the facilitation of motor neurons ${ }^{3-5}$ and the distribution of the effects to various motor neuron pools ${ }^{6}$ are thought to indicate that these short latency effects result from the activation of the fast corticospinal pathway. ${ }^{47}$ The amplitude and latency of the evoked compound muscle action potentials have been shown to be abnormal in a variety of neurological disorders. $^{8-11}$ Transcranial stimulation may be used to detect corticospinal involvement in patients with spinal cord lesions, ${ }^{12} 13$ and this technique could be used to predict outcome after spinal cord injury. ${ }^{14}$

The purpose of this study was twofold. The first was to examine the pattern and characteristics of the short latency corticospinal projec- tions to lower limb spinal motor neurons in patients with incomplete spinal cord lesions. The second was to determine whether there was a relation between the characteristics of these projections and the patient's clinical profile.

\section{Methods}

Patient selection

Subjects with incomplete spinal cord lesions were identified by physicians at Lyndhurst Hospital and screened by one of us (JB). Patients with weakness of the lower limbs who were able to voluntarily contract the tibialis anterior (TA) muscle and showed an increase in resistance to passive stretch and exaggerated deep tendon reflexes were considered for this study. Patients having cardiac pacemakers, intracranial metal implants, or a history of epilepsy were excluded. The experimental procedures were approved by the local ethical review board and informed consent was obtained.

\section{Clinical examination}

A clinical neurological examination was carried out on all patients to document the level and duration of the lesion and the degree of motor and sensory impairment. The overall severity of the spinal cord lesion was assessed and a Frankel grade ( $A$ to $E$ ) assigned. In this grading system grade A corresponds to complete motor and sensory loss; B to complete motor loss, but incomplete sensory loss; $\mathrm{C}$ to incomplete motor loss severe enough to impair function; $D$ to incomplete motor loss with some function (in grades $C$ and $D$ sensation may be variably preserved); and $E$ to normal motor and sensory function. ${ }^{15}$ Strength was scored from 0 (no movement) to 5 (normal). The ankle jerks were scored from 0 (no response) to 4 (brisk), a score of 2 being normal. The flexion response was tested by pinching the toes and was scored from 0 (no response) to 2 (limb movement). The patient's current medication was noted on the day of testing.

\section{Magnetic stimulation}

A Cadwall MES-10 electromagnetic stimulator was used for all studies. When this device is triggered capacitors are discharged, causing a current to flow into a 14 turn circular coil (inside and outside diameter $7.5 \mathrm{~cm}$ and $9.0 \mathrm{~cm}$ respectively) encased in epoxy resin. This current varies the magnetic field, which in turn induces circular currents in nearby conducting tissues. These currents are proportional to the 
rate of change of the magnetic field and the initial stored charge. ${ }^{16}$ The charge is preset according to a linear scale ranging from $0 \%$ to $100 \%$. The maximum magnetic field generated by this stimulator is 2 Tesla (according to the manufacturer's specifications) and the induced current waveform is an underdamped sinusoid lasting $800 \mu \mathrm{s}$ with an initial peak at approximately $5 \mu$ s and a peak of opposite polarity at $135 \mu \mathrm{s}$.

The stimulating coil was positioned flat on the scalp overlying the motor cortex with the centre aligned midway between the vertex and either C3 or C4 (international 10-20 system of electrode placement). ${ }^{17}$ Single stimuli were delivered about every $3 \mathrm{~s}$ at an intensity just below that which produced a contraction of the weakly contracted TA muscle. In patients with spinal cord lesions in whom a threshold intensity for lower limb activation could not be established in this way, the intensity was set $10 \%$ higher than that at which a visible contraction was first evoked in any relaxed upper limb muscle.

\begin{abstract}
Motor unit recordings
Single motor unit recordings were obtained in turn from the TA and SOL muscles contralateral to the site of stimulation by using a concentric needle electrode with a recording surface area of $0.07 \mathrm{~mm}^{2}$ (Dantec 13L49). The needle was positioned near a motor unit that was activated by gentle voluntary contraction or was discharging spontaneously. The motor unit action potentials were amplified (bandpass $10 \mathrm{~Hz}$ to $10 \mathrm{kHz}$ ), extracted with a window discriminator, and displayed on a storage oscilloscope using a delay line. The pulse from the discriminator was led to a loudspeaker and tachometer. Subjects were provided with visual and auditory feedback of the unit's discharges and instantaneous firing rate and were instructed to keep the unit discharging steadily while a minimum of 100 magnetic stimuli were delivered to the contralateral cortex.
\end{abstract}

Peristimulus time histograms (PSTHs) of each individual motor unit's discharge times were generated to record changes in firing probability produced by the magnetic stimulus. The mean background firing probability of a given unit was calculated from the 100 ms prestimulus portion of each PSTH. In the post stimulus portion a coherent cluster of at least two bins (bin width $1 \mathrm{~ms}$ ) with amplitudes greater than the background mean plus two standard deviations was defined as a period of increased firing probability. ${ }^{18}$ The area of the peak of increased firing probability above the mean background level (expressed as extra counts per 1000 stimuli) provided an estimate of the magnitude of the underlying composite excitatory postsynaptic potential (EPSP) produced by the descending volley, and the duration of the PSTH peak provided an estimate of the EPSP rise time. ${ }^{19-22}$ The latencies of the peaks were corrected for the unit's rise time to estimate the conduction time from the brain to the motor unit in the muscle of interest.

The patient data were compared (by $t$ tests) with normal values previously obtained in this laboratory and reported elsewhere. ${ }^{23}$

\section{$F$ waves and central conduction time}

The shortest latency $F$ wave ${ }^{24}$ from 10 trials was measured from TA in response to supramaximal electrical stimulation of the common peroneal nerve at the head of the fibula. Compound muscle action potentials were recorded from TA with the active electrode placed at the approximate location of the needle electrode insertion.

The central conduction time was estimated using the following formula:

Central conduction time $=$ TA latency mag $_{-}$ $((\mathrm{F}$ wave $+\mathrm{M}$ wave $) / 2+1)$

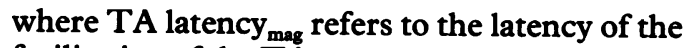
facilitation of the TA motor unit in that subject after magnetic stimulation. All measures refer to their respective latencies (in $\mathrm{ms}$ ), and $1 \mathrm{~ms}$ is allowed for the synaptic delay between the corticospinal axons and the alpha motor neuron. ${ }^{6}$

Table 1 Summary of clinical findings in 16 patients with spinal cord lesions

\begin{tabular}{|c|c|c|c|c|c|c|c|c|c|c|c|}
\hline $\begin{array}{l}\text { Case } \\
\text { No }\end{array}$ & $\begin{array}{l}\text { Age } \\
\text { (years) }\end{array}$ & Sex & Aetiology & Lesion & $\begin{array}{l}\text { Time } \\
\text { after lesion } \\
\text { (years) }\end{array}$ & $\begin{array}{l}\text { Frankel grade } \\
(A-E)\end{array}$ & $\begin{array}{l}T A \text { strength } \\
(0-5)\end{array}$ & $\begin{array}{l}\text { Ankle jerk } \\
(0-4)\end{array}$ & $\begin{array}{l}\text { Flexion response } \\
(0-2)\end{array}$ & $\begin{array}{l}\text { Latency of } T A \\
\text { facilitation } \\
\text { (ms) })^{\star}\end{array}$ & $\begin{array}{l}\text { Estimated } \\
C C T \\
\text { (ms) }\end{array}$ \\
\hline $\begin{array}{r}1 \\
2 \\
3 \\
4 \\
5 \\
6 \\
7 \\
8 \\
9 \\
10 \\
11 \\
12 \\
13 \\
14 \\
15 \\
16\end{array}$ & $\begin{array}{l}26 \\
45 \\
32 \\
36 \\
17 \\
37 \\
27 \\
23 \\
56 \\
24 \\
67 \\
53 \\
53 \\
28 \\
32 \\
31\end{array}$ & $\begin{array}{l}\mathbf{M} \\
\mathbf{M} \\
\mathbf{M} \\
\mathbf{M} \\
\mathbf{M} \\
\mathbf{M} \\
\mathbf{F} \\
\mathbf{M} \\
\mathbf{M} \\
\mathbf{M} \\
\mathbf{M} \\
\mathbf{M} \\
\mathbf{M} \\
\mathbf{M} \\
\mathbf{M} \\
\mathbf{M}\end{array}$ & $\begin{array}{l}\text { Trauma } \\
\text { Trauma } \\
\text { Trauma } \\
\text { Trauma } \\
\text { Trauma } \\
\text { Trauma } \\
\text { Trauma } \\
\text { Trauma } \\
\text { Trauma } \\
\text { Vascular } \\
\text { TSP } \\
\text { TSP } \\
\text { Ep } \\
\text { Trauma } \\
\text { Trauma } \\
\text { Trauma }\end{array}$ & $\begin{array}{l}\mathrm{C}_{4} \\
\mathrm{C}_{4} \\
\mathrm{C}_{5} \\
\mathrm{C}_{5} \\
\mathrm{C}_{6} \\
\mathrm{C}_{6} \\
\mathrm{C}_{6} \\
\mathrm{C}_{7} \\
\mathrm{~T}_{4} \\
\mathrm{~T}_{6} \\
\mathrm{~T}_{8} \\
\mathrm{~T}_{8} \\
\mathrm{~T}_{9} \\
\mathrm{~T}_{10} \\
\mathrm{~T}_{12} \\
\mathrm{~T}_{12}\end{array}$ & $\begin{array}{r}0.5 \\
0 \cdot 2 \\
2.0 \\
0.6 \\
0 \cdot 6 \\
0.7 \\
0.8 \\
3.0 \\
5.5 \\
0.1 \\
17.0 \\
5.0 \\
2.0 \\
1.0 \\
0.5 \\
0.2\end{array}$ & $\begin{array}{l}\text { D } \\
\text { D } \\
\text { C } \\
\text { D } \\
\text { C } \\
\text { D } \\
\text { D } \\
\text { C } \\
\text { D } \\
\text { D } \\
\text { D } \\
\text { C } \\
\text { C } \\
\text { D } \\
\text { D } \\
\text { D }\end{array}$ & $\begin{array}{l}3 \\
3 \\
5 \\
1 \\
1 \\
1 \\
2 \\
2 \\
1 \\
2 \\
2 \\
2 \\
4 \\
5 \\
4 \\
3\end{array}$ & $\begin{array}{l}4 \\
4 \\
3 \\
3 \\
4 \\
4 \\
2 \\
4 \\
3 \\
4 \\
3 \\
3 \\
2 \\
4 \\
4 \\
3\end{array}$ & $\begin{array}{l}1 \\
0 \\
2 \\
1 \\
1 \\
1 \\
1 \\
2 \\
1 \\
1 \\
1 \\
2 \\
2 \\
0 \\
1 \\
0\end{array}$ & $\begin{array}{l}35 \\
36 \\
42 \\
37 \\
42 \\
39 \\
56 \\
31 \\
38 \\
42 \\
41 \\
41 \\
39 \\
60 \\
\text { Absent } \\
38\end{array}$ & $\begin{array}{l}15.9 \\
17.5 \\
\text { ND } \\
18.0 \\
\text { ND } \\
19.0 \\
36.6 \\
10.9 \\
\text { ND } \\
\text { ND } \\
23.9 \\
15 \cdot 4 \\
18.0 \\
\text { ND } \\
\overline{16.4}\end{array}$ \\
\hline
\end{tabular}

*Corrected for the risetime of the motor unit action potential; see text for details on scoring.

TSP = Tropical spastic paresis.

Ep = Ependymoma.

$\mathrm{CCT}=$ Central conduction time

$\mathrm{ND}=$ Not done. 
Figure 1 Representative PSTHs from a normal subject (left) and patient (case 12) (right) showing changes in the firing probability of single $T A$ and $S O L$ motor neurons in response to magnetic stimulation applied over the contralateral motor cortex at time zero (arrowhead). There is a strong facilitation of $T A$ motor units (top) but not of SOL motor units (bottom). The apparent facilitation at time zero of the PSTHs from the patient is due to stimulus artefact.

Normal

$\mathrm{SCI}$

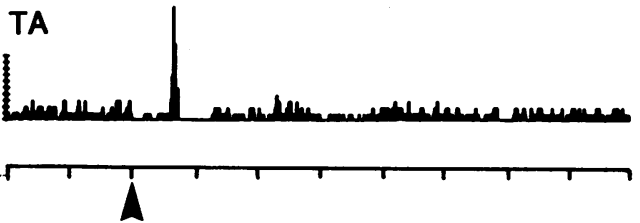

SOL

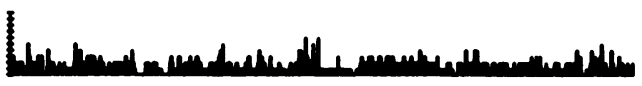

$-100$

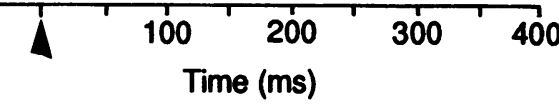

00 - 100

TA

inmenardend
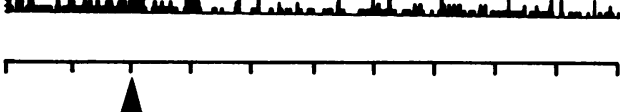

SOL

(
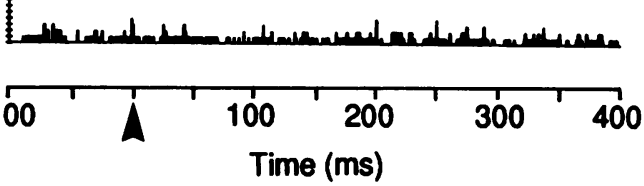

lesions $(41.1 \mathrm{~ms})$ than in normal subjects

Results

Clinical findings

Studies were carried out on 33 normal subjects (mean age 25.0 (SD 6.7)) and on 16 patients with incomplete spinal cord lesions (mean age $36 \cdot 7(14 \cdot 1)$ ) due to trauma (12 patients), tropical spastic paraparesis (two), ependymoma (one), or vascular lesion (one). All but one patient (case 8) were able to take a step with aids and one patient (case 7) walked regularly with canes. All patients had Frankel grades of $\mathrm{C}$ or $\mathrm{D}$ and all had some sensory loss. A summary of the clinical findings is presented in table 1.

\section{Motor unit recordings}

Magnetic stimuli applied to the contralateral hemisphere resulted in strong facilitation of TA motor units in all normal subjects and in 15 out of 16 patients. In the one patient in whom a response was not observed the stimulus may have been insufficient, although the intensity was chosen according to the criteria described in the methods. Only three of the normal subjects and three of the patients showed short latency facilitation of SOL motor units and in all cases the facilitation was much less than that of TA units. Typical recordings taken from a normal subject and a patient with a spinal cord lesion are shown in fig 1 . The means of the PSTH peak areas (normalised to 1000 stimuli) for both groups are shown in fig 2 . The relative magnitudes of the facilitations of TA and SOL motor units are similar in normal subjects and patients with spinal cord lesions.

The characteristics of the shortest latency PSTH peaks of TA motor units are summarised in table 2. (The general absence of responses in SOL precluded analysis of the short latency effects on these motor units.) The mean latency of the facilitation of TA units was significantly longer in patients with spinal cord
Table 2 Characteristics of short latency facilitations in $T A$ motor neurons in patients with spinal cord lesions and normal subjects. Values are means (SD)

\begin{tabular}{llllll}
\hline & Recording type & $n$ & $\begin{array}{l}\text { Extra counts/ } \\
1000 \text { stimuli }\end{array}$ & $\begin{array}{l}\text { Mean onset } \\
\text { latency (ms) }\end{array}$ & $\begin{array}{l}\text { Mean duration } \\
\text { (ms) }\end{array}$ \\
\hline Patients & SU & 12 & $199 \cdot 2(39 \cdot 9)$ & $40 \cdot 1(1 \cdot 7)$ & $7 \cdot 4(1 \cdot 2)$ \\
Normal & SU + MU & 16 & $200 \cdot 8(32 \cdot 8)$ & $41 \cdot 1(1 \cdot 9)$ & $7 \cdot 5(1 \cdot 0)$ \\
\hline
\end{tabular}

SU $=$ Single unit.

MU = Multi-unit.
$(27 \cdot 1 \mathrm{~ms}), t_{(\mathrm{df}=47)}=9.06, \mathrm{p}<0.001$. This is illustrated in fig 3 , which shows PSTHs obtained from TA motor units in a patient and a normal subject of identical height. In only one patient (case 8) did the latency of the facilitation of TA fall within two standard deviations of the mean calculated for normal subjects.

The latency of TA facilitation will depend on the subject's height and on the conduction velocity of the alpha motor neuron axon. The mean heights for the two groups were 167.9 $(7 \cdot 5) \mathrm{cm}$ (normal subjects) and $174.8(6 \cdot 1) \mathrm{cm}$ (patients with spinal cord lesions), $t_{(\mathrm{df}=47)}=$ $2 \cdot 71, \mathrm{p}<0.01$. There was no evidence that the conduction velocity in the alpha motor neuron axon was slow in the patient group. $F$ waves were measured for 10 patients, nine of whom showed delayed facilitation of TA motor units after magnetic stimulation. In all cases the $F$ wave latencies were normal. ${ }^{13}$

By subtracting the peripheral conduction time (estimated from the $F$ wave) from the total latency it is possible to estimate the central conduction time. The average estimated central conduction time in the patients with spinal cord lesions was $19.2(6.9) \mathrm{ms}$ with a range from $10.9 \mathrm{~ms}$ to $36.6 \mathrm{~ms}$. Mean central conduction times for normal subjects are between $9.5 \mathrm{~ms}^{13}$ and $14.8 \mathrm{~ms}^{25}$

The mean duration of the peak of increased firing probability in TA motor neurons was significantly longer in patients than in normal subjects $\left(t_{(d f=43)}=2.61, p<0.02\right)$. The width (duration) of a peak is positively related to its

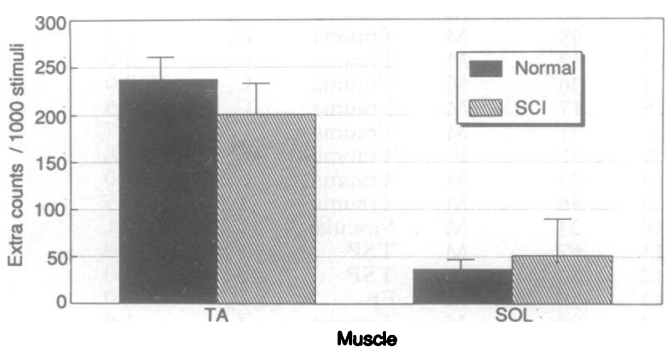

Figure 2 Mean amplitudes ( $S E$ ) of the periods of increased firing probability (expressed as extra counts per 1000 stimuli) in TA and SOL motor units from 33 normal subjects and 12 patients with spinal cord lesions (single unit studies only). The pattern of activation is the same for both groups. 


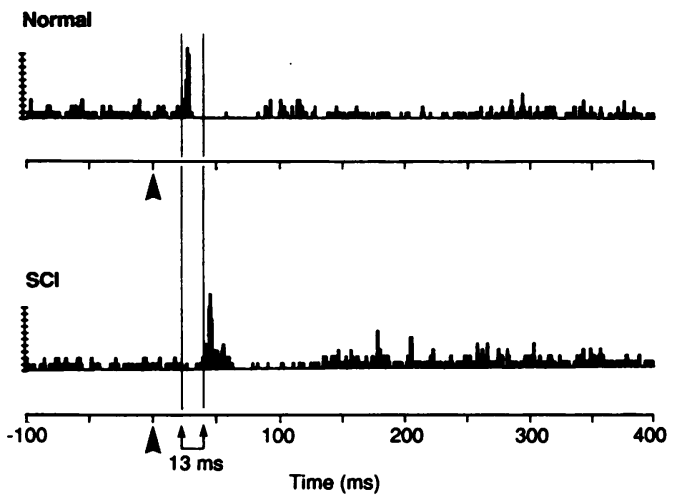

Figure 3 PSTH of a TA motor unit from a normal subject (top) and patient (case 13) (bottom) in response to 100 subthreshold magnetic stimuli applied over the contralateral motor cortex at time zero (arrowhead). The heights of these two individuals are identical $(168 \mathrm{~cm})$. The onset of the $T A$ facilitation in the patient is 13 ms later than that of the normal subject (after correction for the rise time of the motor unit action potentials).

magnitude, ${ }^{26}$ but this cannot account for our findings. There was no difference between the magnitudes of the peaks in patients and normal subjects $\left(t_{(d f=43)}=0.84, p>0.40\right)$, and first order regression analysis of the relation between peak area and duration (fig 4) shows similar slopes but different $y$ intercepts for the two populations $(\mathrm{p}<0.01)$.

Some patients had difficulty maintaining a steady contraction of the TA muscle and it was not possible to obtain recordings without occasional contamination by other units. As these patients generally had the greatest motor deficit and might have shown an alteration in projections not seen in other patients, their "multi-unit" recordings were analysed. As shown in table 2, the addition of these data made little difference to the results.

There was no apparent relation between the patient's clinical profile and the magnitude, latency, or duration of the facilitation observed in TA. Correlation coefficients between TA strength and PSTH peak amplitude or latency and between the time post-lesion and PSTH amplitude or latency were in all cases less than $0 \cdot 20$.

\section{Discussion}

Magnetic stimulation over the motor cortex in normal subjects produces strong short latency facilitation of. TA motor neurons but not of SOL motor neurons. This has been interpreted

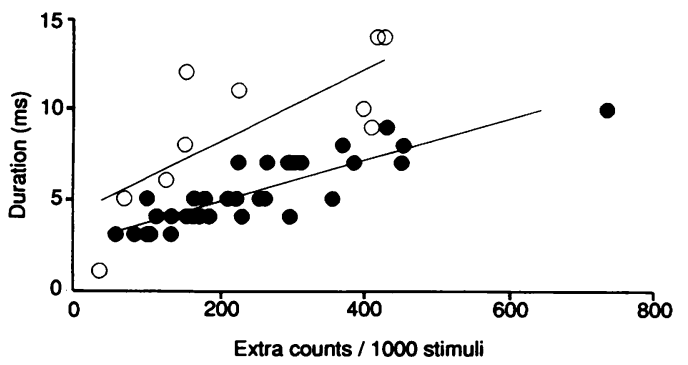

Figure 4 Relation between the magnitude and duration of the PSTH peaks obtained from TA motor units in normal subjects (O) and patients with spinal cord lesions (O). as reflecting the relative strength of the projections of the fast conducting corticospinal pathway to these motor neurons. ${ }^{2327}$ This pattern seems to be the same in patients with spinal cord lesions, suggesting that the projection pattern of the corticospinal tract is not changed as a result of adult onset spinal cord lesions, even when these are long standing (up to 17 years). In contrast, the pattern of corticospinal projections is altered after lesions of the developing brain. ${ }^{23} 27$

The magnitude of the facilitation of TA motor units in the patients with spinal cord lesions was about the same as in normal subjects. This may be related to the selection of patients (who had to be able to contract TA) and to the way the intensity of the stimulus was chosen. The responses were, however, significantly delayed. The delay was probably not due to an increased peripheral conduction time as the $F$ wave latencies were normal. $F$ waves represent activity in large diameter alpha motor neuron axons whereas the motor units first recruited by voluntary contraction are probably of small diameter. If the delays in the PSTH peaks were due to an increased peripheral conduction time in the patients with spinal cord lesions there could have been selective slowing of conduction in small diameter alpha motor neuron axons. The delay is more likely to be occurring in the central nervous system. The patient group was on average slightly taller (by $7 \mathrm{~cm}$ ) than the normal subjects, but this could not account for the longer latencies since this difference in height would be expected to produce an increase in latency of about $0.5 \mathrm{~ms}^{28}$ The possibility that we mistook a late response to magnetic stimulation for the short latency facilitation is unlikely as these responses rarely occur in the absence of short latency facilitation. ${ }^{29}$ Furthermore, the late responses recorded from TA occur at latencies in excess of $100 \mathrm{~ms}^{29}$ The delayed facilitation of TA units in the patients with spinal cord lesions is therefore attributed to pathological changes in the corticospinal tract.

If so, there are several possible explanations. It could be that the fastest conducting corticospinal axons have been selectively lost and that the prolonged central conduction time reflects conduction in the smaller $(<4 \mu \mathrm{m})$, slower conducting axons which constitute about $90 \%$ of the corticospinal tract. ${ }^{30}$ If this were the case the central conduction times, assuming a conduction velocity of $20 \mathrm{~m} / \mathrm{s}$ over a distance of $560 \mathrm{~mm},{ }^{31}$ would be expected to be more than $28 \mathrm{~ms}$. Our data do not support this.

An alternative explanation is that the descending volley is transmitted via a pathway other than the direct (monosynaptic) corticospinal tract. For example, a facilitatory pathway may exist whose effects are normally hidden in the period of inhibition which follows alpha motor neuron activation by the corticospinal volley. ${ }^{32}$ Only the rubrospinal tract is known to have a similar pattern of projections onto spinal motor neurons, but it is believed to be vestigial in humans. ${ }^{33}$

A third possibility is that the conduction in the zone of the lesion has been slowed owing to 
focal demyelination. Assuming normal central conduction to be about $65 \mathrm{~m} / \mathrm{s}^{34}$ and conduction in demyelinated fibres to be $2 \mathrm{~m} / \mathrm{s},{ }^{35}$ then demyelination over a $15-58 \mathrm{~mm}$ (mean $22 \mathrm{~mm}$ ) segment would be required to explain total central conduction times of 16-37 ms (mean $19 \mathrm{~ms}$ ).

Studies describing the pathology after spinal cord injury in humans report macroscopic cord lesions extending longitudinally $1-5 \mathrm{~cm}^{36}$ and microscopic lesions including haemorrhages and disruption of myelin sheaths throughout 4-5 segments adjacent to the lesion. ${ }^{37}$ This being the case, a demyelinated segment extending from $15-58 \mathrm{~mm}$ in length would be quite possible. Local demyelination would also explain the wider PSTH peaks in the patient group as the duration of the PSTH peak (which is related to the rise time of the underlying composite EPSP) would be expected to be longer because of the temporal dispersion from the non-uniformity of conduction velocities in the demyelinated region. In normal subjects the facilitation of TA is remarkably brief, suggesting that the corticospinal axons activated by cortical stimulation have very similar conduction velocities. Magnetic resonance imaging would have been helpful in determining the presence and extent of demyelination in patients with spinal cord injury ${ }^{38}$ but was not available.

Similar delays in cortically evoked muscle activation have been observed in cases of cervical spondylosis, trauma, ${ }^{12}$ and stenosis. ${ }^{13}$ Like Masur et $a l^{13}$ we were unable to show a significant correlation between the magnitude of the delay and the patient's functional abilities. Delayed central conduction may be related more strongly to disability in degenerative central nervous system diseases such as multiple sclerosis. ${ }^{9}$

In conclusion, this study provides evidence that the pattern of corticospinal projections to lower limb spinal motor neurons is not altered after incomplete spinal cord injury. The TA facilitation in response to cortical magnetic stimulation is significantly delayed in affected patients, probably reflecting slowing of conduction in the corticospinal pathway. The degree of slowing was not shown to be related to the clinical deficit in this group of patients.

This research has been funded by the Ontario Easter Seal Research Institute and the Canadian Medical Research Council. We thank the patients and staff of Lyndhurst Hospital for their support.

1 Merton PA, Morton HB. Stimulation of the cerebral cortex in the intact human subject. Nature 1980;285:227.

2 Barker AT, Freeston IL, Jalinous R, Merton PA, Morton HB. Magnetic stimulation of the human brain. J Physiol (Lond) 1985;369:3P

3 Brouwer B, Ashby P, Midroni G. Excitability of corticospinal neurons during tonic musc

4 Day BL Dressler D, Maertens de Noordhout A, Marsden $\mathrm{CD}$, Nakashima K, Rothwell JC, et al. Electric and magnetic stimulation of the human motor cortex: surface EMG and single motor unit responses. J Physiol (Lond) EMG and single

5 Zarola F, Caramia MD, Paradiso C, Mariorenzi R, Martino G, Traversa $R$, et al. Single fiber motor evoked potentials $\mathrm{G}$, Traversa $\mathrm{R}$, et al. Single fiber motor evoked potentials to brain, spinal roots and nerve stimulation. Comparisons of the 'central' and 'peripheral' jitter to
electric stimuli. Brain Res 1989;495:217-24.
6 Brouwer B, Ashby P. Corticospinal projections to upper and lower limb spinal motoneurons in man. $E E G$ Clin Neurophysiol 1990;76:509-19.

7 Edgley SA, Eyre JA, Lemon RN, Miller S. Excitation of the corticospinal tract by electromagnetic and electrical stimulation of the scalp in the macaque monkey. J Physio (Lond) 1990;425:301-20.

8 Mills KR, Murray NMF, Hess CW. Magnetic and electrical transcranial brain stimulation: physiological mechanism and clinical applications. Neurosurgery 1987;20:164-8.

9 Ingram DA, Thompson AJ, Swash M. Central motor conduction in multiple sclerosis: evaluation of abnormalities revealed by transcutaneous magnetic abnormalities revealed by transcutaneous magnetic 1988;51:487-94.

10 Eisen AA, Shtybel W. AAEM minimonograph $\$ 35$ : clinical experience with transcranial magnetic stimulation. Muscle Nerve 1990;13:995-1011.

11 Yang BJ, Brouwer B, Hajek VE, Ashby P. Magnetic stimulation of short latency corticospinal pathways following unilateral cerebral infarction. Canadian Journal of Rehabilitation 1990;4:39-45.

12 Thompson PD, Dick JPR, Asselman P, Griffin GB, Day BL, Rothwell JC, et al. Examination of motor function in lesions of the spinal cord by stimulation of the motor cortex. Ann Neurol 1987;21:389-96.

13 Masur H, Elger CE, Render K, Fahrendorf G, Ludolph AC. Functional deficits of central sensory and motor pathways in patients with cervical spinal stenosis: a study of SEPs in patients with cervical spinal stenosis: a study of SEPs and EMG responses to non-invasive
EEG Clin Neurophysiol $1989 ; 74: 450-7$.

$14 \mathrm{Katz}$ RT, VandenBerg C, Weinberger D, Cadwell J. Magnetoelectric stimulation of human motor cortex normal values and potential safety issues in spinal cord injury. Arch Phys Med Rehabil 1990;71:597-600.

15 Frankel HL, Hancock DP, Hyslop G, Melzack J, Michaelis LS, Ungar GH, et al. The value of postural reduction in the initial management of closed injuries of the spine with paraplegia and tetraplegia. Paraplegia 1969;7:179-92.

16 Barker AT, Freeston IL, Jalinous R, Jarrat JA. Magnetic stimulation of the human brain and peripheral nervous system: an introduction and the results of an initial clinical evaluation. Neurosurgery 1987;20:100-9.

17 Jasper HH. Report of the committee on methods of clinical examination in electroencephalography. $E E G$ Clin Neurophysiol 1958;10:370-5.

18 Mao CC, Ashby P, Wang M, McCrea D. Synaptic connections from large muscle afferents to the motoneurons of tions from large muscle afferents to the motoneurons of various
$341-50$.

19 Ashby P, Zilm D. Characteristics of postsynaptic potentials produced in single human motoneurons by homonymous group I volleys. Exp Brain Res 1982;47:41-8.

20 Fetz EE, Gustafsson B. Relation between shapes of postsynaptic potentials and changes in firing probability of cat motoneurons. J Physiol (Lond) 1983;341:387-410.

21 Cope TC, Fetz EE, Matsumura M. Cross-correlation assessment of synaptic strength of single la fiber connections with triceps surae motoneurons in cats. $J$ Physiol (Lond) 1987;390:161-88.

22 Midroni G, Ashby P. How synaptic noise may affect crosscorrelations. J Neurosci Methods 1989;27:1-12.

23 Brouwer B, Ashby P. Altered corticospinal projections to lower limb motoneurons in subjects with cerebral palsy. Brain 1991;114:1395-1407.

24 Kimura J. Electrodiagnosis in diseases of nerve and muscle: principles and practice. Philadelphia: Davis FA, 1983.

$25 \mathrm{Chu}$ N-S. Motor evoked potentials with magnetic stimulation: correlations with height. EEG Clin Neurophysiol 1989;74:481-5.

26 Mailis A, Ashby P. Alterations in group 1a projections to motoneurons following spinal lesions in man. $J$ Neurophysiol 1990;64:637-47.

27 Brouwer B, Ashby P. Do injuries to the developing human brain alter corticospinal projections? Neurosci Lett 1990; 108:225-30.

28 Claus D. Central motor conduction: methods and normal results. Muscle Nerve 1990;13:1125-32.

29 Holmgren H, Larsson L-E, Pedersen S. Late muscular olmgren $\mathrm{H}$, Larsson $\mathrm{L}-\mathrm{E}$, Pedersen $\mathrm{S}$. Late muscular Clin Neurophysiol 1990;75:161-72.

30 DavidoffRA. The pyramidal tract Neurology 1990;40:332-9.

31 Brouwer B. Corticospinal projections in man: are they altered in cerebral palsy? [Doctoral dissertation.] Institute of Medical Science, University of Toronto, 1990.

2 Inghilleri M, Berardelli A, Cruccu G, Priori A, Manfredi $M$. Motor potentials evoked by paired cortical stimuli. $E E G$ Clin Neurophysiol 1990;77:382-9.

33 Nathan PW, Smith MC. The rubrospinal and central tegmental tracts in man. Brain 1982;105:223-69.

34 Rothwell JC, Thompson PD, Day BL, Dick JPR, Kachi T, Cowan JMA, et al. Motor cortex stimulation in intact man. Brain 1987;110:1173-90.

35 Boyd IA, Davey MR. Compositions of peripheral nerves. Edinburgh: $E$ and S Livingstone, 1968.

36 Bedbrook GM. Some pertinent observations on the pathology of traumatic spinal paralysis. Paraplegia pathology of

37 Holmes G. Spinal injuries of warfare. BMJ 1915;ii:769-74.

38 Schaefer DM, Flanders A, Northrup BE, Doan HT, Osterholm JL. Magnetic resonance imaging of acute cervical spinal trauma correlation with severity of neurologic injury. Spine 1989;14:1090-5. 